\title{
Measuring the Effective Dispersal of an Emerging Coastal Weed, Euphorbia Paralias (Sea Spurge), To Help Inform its Eradication.
}

Fiona Joanne Thomson ( $\square$ fthomson@doc.govt.nz)

New Zealand Department of Conservation https://orcid.org/0000-0002-0365-8823

\section{Research Article}

Keywords: Sea spurge, dispersal distance, weed, eradication, biosecurity

Posted Date: October 18th, 2021

DOl: https://doi.org/10.21203/rs.3.rs-648327/v1

License: (c) (1) This work is licensed under a Creative Commons Attribution 4.0 International License.

Read Full License 


\section{Abstract}

Understanding dispersal and establishment patterns of invasive plant species is critical information to help control and eradicate their populations. Euphorbia paralias, sea spurge, is a highly invasive weed that can be a serious threat to coastal environments. Two recent incursions of E. paralias on New Zealand's coastline consisted of one reproductive adult surrounded by several hundred juveniles, providing the opportunity to gather effective dispersal distance data for this species. Using these two separate populations effective dispersal distances curves were created for E. paralias. It was found one adult led to the establishment of 213 healthy plants at NZ's southern-most incursion and 484 healthy plants at the northern-most incursion. All plants were subsequently removed from the site. The maximum effective dispersal distance of $15.8 \mathrm{~m}$ on land for $E$. paralias was larger than would be predicted by the majority of trait-based dispersal distance models and the estimate of $\sim 2 \mathrm{~m}$ in the literature. These results show that E. paralias can establish large healthy populations, making it a considerable threat to coastal environments. However, populations around an adult plant are fairly concentrated at the very early stages of invasion ( $90 \%$ of offspring $<5.5 \mathrm{~m}$ from the adult) providing opportunities to remove the seed bank at incursion sites. Early detection of E. paralias populations using comprehensive surveillance and removal of any new populations (seed and establishing plants) will be essential components for the success in any eradication programme for sea spurge.

\section{Introduction}

Sea spurge, Euphorbia paralias (Euphorbiaceae) can be a highly invasive coastal weed outside of its native range. It is of high conservation concern once established because of its ability to form large monocultures, displacing native vegetation, and transforming habitat for coastal fauna and flora (Kelly 2015). E. paralias is also of recreation concern due to the toxic, milky sap that is released when the plant is damaged, that irritates skin and damages eyes with contact. E. paralias' invasive success has hinged on its ability to establish readily in coastal environments (c. 4 months from establishment to flowering in New Zealand; Velvin and Embling 2014) and to produce large quantities of seed which can be dispersed long distances on ocean currents (Heyligers 2002; Kelly 2015). Localised dispersal is through ballistic dispersal (seeds being explosively released from seed pods) with the majority of seeds thought to disperse $<2 \mathrm{~m}$ (Heyligers 2002), however there is little knowledge of its dispersal patterns on land.

A critical part of weed management is to understand the species' dispersal pathways and the dispersal distances it can achieve. However, obtaining dispersal distance data is notoriously challenging in plant populations due to difficulties relating parent plants to their offspring (effective dispersal), or tracking the dispersal distances seeds reach (actual dispersal) (Rogers et al. 2019). It is rare in invasion ecology to find a population at the start of the invasion process where there is only one reproductive adult plant, surrounded by establishing juveniles. Yet, this type of population provides a unique opportunity to capture the effective dispersal kernel. Knowledge on the effective dispersal distance kernel of E. paralias is critical to understanding its spread and to develop robust control techniques. 
E. paralias is a serious pest in temperate regions in the pacific. Since its arrival in Australia approximately 90 years ago, E. paralias has become widespread along Australia's southern and south-eastern coastlines (Heyligers 2002). In New Zealand (NZ) concern for E. paralias's possible impacts has led to it receiving 'Unwanted Organism' status with an aim of eradicating any populations that establish on NZ's shorelines (Velvin and Embling 2014). Since 2012, five confirmed incursions of E. paralias have occurred in NZ, with all plants being removed when found. These incursions are thought to be from seed that has travelled by ocean current from Australia, to be deposited on the NZ shoreline. For the two most recent incursions, they each consisted of 1 reproductive adult surrounded by juveniles, allowing for effective dispersal distance curves to be developed. The aims of this study, using two recent incursions of E. paralias are: 1) Assess population health and size at the incursion sites, 2) develop the effective dispersal kernel for $E$. paralias and 3) compare dispersal distance data in the field with simple trait-based dispersal models.

\section{Methods}

In 2020, E. paralias rapidly expanded its range in NZ (approximately $76 \mathrm{~km}$ to the south and $110 \mathrm{~km}$ to the north of previously known incursions). The southern-most incursion of E. paralias found in August 2020 was at Scotts Beach, near the Heaphy track in Kahurangi National Park, Karamea. The northern-most incursion of E. paralias found in October 2020 was at Karekare beach near Auckland. The reproductive adult plants were removed from each site and their locations marked with a pole. Adult plants were identified and were estimated to be $>3$ years (Scotts Beach) and $>1$ year (Karekare) (Frances Velvin, Trevor James pers. comm.), indicating more than one season of seeding events may have occurred. At both sites no other plants were found in the surrounding area to have produced seeds, although one plant in Karekare had undeveloped flowers. At each site it was expected the juvenile plants surrounding the reproductive plant are offspring of the reproductive plant, although some juvenile plants could be from the same dispersal event that led to the establishment of the adult. All E. paralias plants were removed from the sites by hand. The plants had their growth status (branching, flowering and/or seeding), health status (dead; major loss or damage to vegetative material ( $>50 \%$ ); minor loss or damage of vegetative material (51-95\%); healthy $(<5 \%)$ ) and their distance and bearing from the adult plant recorded. Plant heights were recorded except for plants $<4 \mathrm{~cm}$ tall. To predict the maximum expected dispersal distance for a ballochorous species I used the dispeRsal package (Tamme et al. 2011). This package uses simple plant trait data to predict species maximum dispersal distances. Seed mass data $(5.8 \mathrm{mg})$ was obtained from Royal Botanic Gardens Kew (2020), maximum plant height data (1m) was obtained from New Zealand Plant Conservation Network (2020). Most plants in NZ are $<70 \mathrm{~cm}$ tall so maximum dispersal distance may be an overestimated. A t-test on the log transformed data was done to compare dispersal distances between sites. All analyses were done in $\mathrm{R}$.

\section{Results \& Discussion}

I found one adult E. paralias plant led to the localised establishment of 213 plants at NZ's southern-most incursion (Scotts Beach) and 484 plants at the northern-most (Karekare) incursion (Table 1). The plant 
populations were extremely healthy with $96 \%$ of plants at both sites having $<5 \%$ vegetation damage. The majority of plants were seedlings $<4 \mathrm{~cm}$ tall (Fig. 1). At Scotts beach seedlings tended to be closer to the adult plant, whereas at Karekare seedlings were distributed along the dispersal gradient (Fig. 2). Although the date of establishment is unknown, the results indicate that these populations are relatively new, healthy, and without control would rapidly expand at both sites. These findings also indicate $E$. paralias would become a major pest along the majority of NZ's coastlines, and strongly support it's Unwanted Organism status and the requirement for its continued eradication. For other countries with coastal areas that have similar climatic envelopes as NZ and South-Eastern Australia, eradication of this plant should be considered if populations are discovered.

Plants established on average further from the adult plant at Karekare than at Scotts Beach (Table 1, $t=$ $-9.445, \mathrm{df}=288, \mathrm{p}$-value $=<0.001)$. The percentiles of effective dispersal distance were also all further at Karekare than Scotts Beach (Table 1). Plant distributions around the adult plant also varied between sites (Fig. 3). Approximately three quarters of established plants occurred inland from the adult at Scotts beach, while at Karekare the distribution was more uniform around the adult (Fig. 3). I expect that the arrangement of the habitat at each site is the main driver of this result. At Scotts Beach the offspring of the adult plant were restricted in the habitat they could establish, due to the adult establishing in a relatively narrow surge zone. The bush edge, where shade would inhibit establishment, was approximately $8.5 \mathrm{~m}$ inland from the adult plant, while the high tide mark on the seaward side was $13 \mathrm{~m}$ away. Seed may have been washed away on the seaward side of the adult plant at Scotts Beach, but a survey $15 \mathrm{~km}$ either side of the Scotts Beach infestation found no other populations. Yang et al. (2012), in a study of seed dispersal of coastal species found that $90 \%$ of their buoyant twig segments (used to mimic seeds) returned to the same section of coast where they were released, with the majority of those settling tens of metres from the release point. At Scotts Beach seed may have been washed inland by sea surges rather than washed out to sea, resulting in the observed fan shaped distribution (Fig. 3). At Karekare, the more uniform distribution of seeds may be due to the adult establishing in the back dune of a large dune system away from the storm surge zone, and with potential habitat for $>80 \mathrm{~m}$ in all directions (Fig. 2).

The maximum effective dispersal distance of E. paralias (15.8m; Table 1) was 3.6 times further than the maximum dispersal distance predicted by the trait based dispeRsal model (Tamme et al. 2014) for ballochory for herbaceous species $(4.4 \mathrm{~m})$ but approximately half the predicted distance if $E$. paralias is considered a shrub $(27.8 \mathrm{~m})$. The 50 th and 95 th percentiles for both sites (Fig. 2; Table 1) were greater than those predicted in Bullock et al. (2017) for ballistic herbaceous species $(<1 \mathrm{~m}$ in height and $<10 \mathrm{mg}$ seed size; 50 th $=1.063 \mathrm{~m}, 95 \mathrm{th}=4.926)$ or wind dispersed herbaceous species $(0.1-0.8 \mathrm{~m}$ in height; 50 th $=$ $0.129 \mathrm{~m}, 95 \mathrm{th}=0.679 \mathrm{~m}$ ). The greater dispersal distance I observed compared to those predicted by the majority of dispersal models is probably due to the effective dispersal distances being impacted by secondary dispersal of seeds by wind. At Karekare, I observed seeds easily rolling along the top of the sand with a wind gust, dispersing seeds further than they would have initially been dispersed ballistically. The results support recent calls for developing dispersal kernels that consider the total dispersal kernel where dispersal by multiple vectors are considered (Rogers et al. 2019). This is especially important when 
managing invasive species where underestimation of the dispersal kernel by looking at a singular vector could lead to underestimation of spread and missed individuals or populations during surveillance monitoring.

A strong surveillance programme and management of dispersal and establishment pathways is needed to keep coastlines free from E. paralias. For Australia and New Zealand, targeted control of seed source populations where seed has the highest likelihood of reaching NZ or Australia's more northern coastlines will reduce the probability of long-distance dispersal events occurring. Identification of seed source populations and high likelihood establishment sites is a critical avenue for future research. Such research will also help with the location and timing for a national surveillance programme in NZ. Development of multiple tools such as remote sensing and weed detection dogs to increase the probability of detecting plants and to delimit incursions would be valuable (Cherry et al. 2016). Future surveillance monitoring for E. paralias should consider the wind patterns at sites when searching for new individuals or populations.

To minimise secondary dispersal by wind or ocean currents removal of the seedbank could be considered at incursion sites. These results provide quick, realistic boundaries for delimiting the potential seedbank, e.g. $90 \%$ of presumed offspring were within $5.5 \mathrm{~m}$ of the adult plant at both sites (Table 1 ). More in-depth analysis of the seedbank through soil sampling may provide better results but are more labour intensive. Development of low cost, effective methods for removal or treatment of the seedbank would be valuable for future eradication efforts.

In conclusion, E. paralias is a highly invasive and transformative weed that without control can become a serious threat for temperate coastal ecosystems. The establishment of a single adult can quickly lead to the localised establishment of $>450$ healthy plants. The land-based maximum dispersal distance for $E$. paralias is larger than would be predicted by trait-based models alone, however the land-based maximum dispersal distance still appears to be relatively small $(15.8 \mathrm{~m})$. Early detection of E. paralias populations through a comprehensive surveillance program and removal of any new populations (seed and establishing plants) will be important for any region or country attempting zero-density or eradication of E. paralias.

\section{Declarations}

Funding This research was supported by the Department of Conservation.

Conflicts of interest/Competing interests (include appropriate disclosures) The author has no conflicts of interest to declare that are relevant to the content of this article.

Ethics approval Not applicable

Consent to participate Not applicable

Consent for publication (include appropriate statements) Not applicable

Availability of data and material (data transparency)

The datasets generated and / or analysed during the current study have not been released as they are part of an ongoing field trial. They may be requested from the corresponding author 
Code availability Not Applicable

Authors' contributions FJT designed the study, collated and analysed the data and wrote the manuscript.

\section{Acknowledgements}

A large thank you to Department of Conservation staff: Kate McAlpine, David Havell, Jane Williams, Brent Fagan and Deb Price, and Auckland Council staff Hugo Geddes, Rowena Gilchrist and Holly Cox for field assistance, data collection and/or comments on the manuscript. Frances Velvin from the Ministry of Primary Industries for support and initial scoping of methods.

\section{References}

1. Bullock JM, Mallada González L, Tamme R, Götzenberger L, White SM, Pärtel M, Hooftman DAP (2017) A synthesis of empirical plant dispersal kernels. Journal of Ecology 105: 6-19. https://doi.org/10.1111/1365-2745.12666

2. Cherry H, Constantine A, Primrose K, Hauser C, Tasker K (2016) It takes a village: detection dogs, partnerships and volunteers aid hawkweed eradication in mainland Australia. Proceedings of the 20th Australasian Weeds Conference, 11-15 September, Perth, Western Australia, eds Randall R, Lloyd S, Borger S. (Weeds Society of Western Australia, Perth).

3. Heyligers PC (2002) The spread of the introduced Euphorbia paralias (Euphorbiaceae) along the mainland coast of south-eastern Australia. Cunninghamia 7: 563-578.

4. Kelly LJM (2015) Patterns of sea spurge (Euphorbia paralias) invasion in New South Wales, Australia. Honours Thesis, The University of Wollongong.

5. New Zealand Plant Conservation Network (2020) Euphorbia paralias. https://www.nzpcn.org.nz/flora/species/euphorbia-paralias/. Accessed 15 December 2020

6. Rogers HS, Beckman NG, Hartig F, Johnson JS, Pufal G, Shea K, Zurell D, Bullock JM, Cantrell RS, Loiselle B, Pejchar L, Razafindratsima OH, Sandor ME, Schupp EW, Strickland WC, Zambrano J (2019) The total dispersal kernel: a review and future directions. AoB PLANTS 11: plz042; doi: 10.1093/aobpla/plz042

7. Royal Botanic Gardens Kew (2020) Seed Information Database (SID). Version 7.1. Available from: http://data.kew.org/sid/. Accessed 15 December 2020

8. Tamme R, Götzenberger L, Zobel M, Bullock JM, Hooftman DAP, Kaasik A, Pärtel M (2014) Predicting species' maximum dispersal distances from simple plant traits. Ecology 95: 505-513.

9. Velvin FG, Embling DR (2014) Sea spurge (Euphorbia paralias): using plant development to inform the eradication programme in New Zealand. Proceedings of the $19^{\text {th }}$ Australasian Weeds Conference, 1-4 September, Hobart, Tasmania, Australia, ed M. Baker (Tasmanian Weed Society).

10. Yang H, Lu Q, Wu B, Zhang J (2012) Seed dispersal of East Asian coastal dune plants via seawater short and long distance dispersal. Flora- Morphology, Distribution, Functional Ecology of Plants 207: 701-706 


\section{Tables}

Table 1

Dispersal distance measures for Euphorbia paralias (sea spurge) plants established around an adult plant at Karekare in Auckland and Scotts Beach, Karamea

\begin{tabular}{|lll|}
\hline Dispersal distance $(\mathrm{m})$ & Karekare & Scotts Beach \\
\hline Mean & $3.26(0.09 \mathrm{SE})$ & $2.06(0.14 \mathrm{SE})$ \\
\hline Maximum & 15.80 & 15.46 \\
\hline Minimum & 0.20 & 0.13 \\
\hline Median (50th) & 2.89 & 1.33 \\
\hline 75th & 4.21 & 2.93 \\
\hline 90th & 5.47 & 5.23 \\
\hline 95th & 7.43 & 5.79 \\
\hline 99th & 8.96 & 6.65 \\
\hline Number of plants & 484 & 213 \\
\hline
\end{tabular}

Figures 

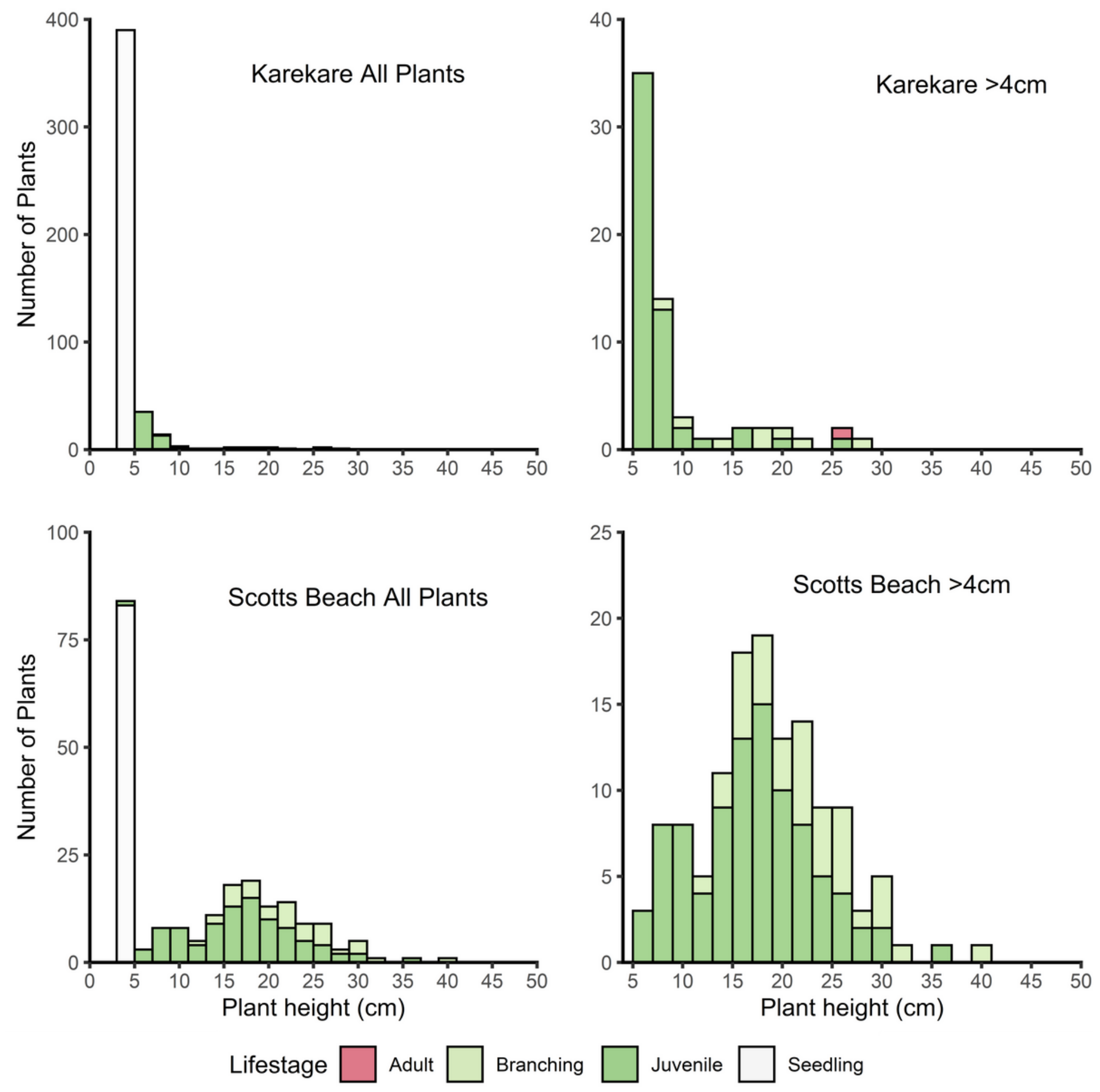

\section{Figure 1}

Height distribution of Euphorbia paralias (sea spurge) plants that are presumed offspring of the adult plant at Karekare and Scotts Beach. Graphs on the left includes all offspring while graphs on the right exclude seedlings $(<4 \mathrm{~cm})$ to make the distribution easier to see. Lifestages are seedling (plants $<4 \mathrm{~cm}$ ), juvenile (single stem non-reproductive plants), branching (multi-stem non-reproductive plants) and adult (flowering and/or seeding plant) 

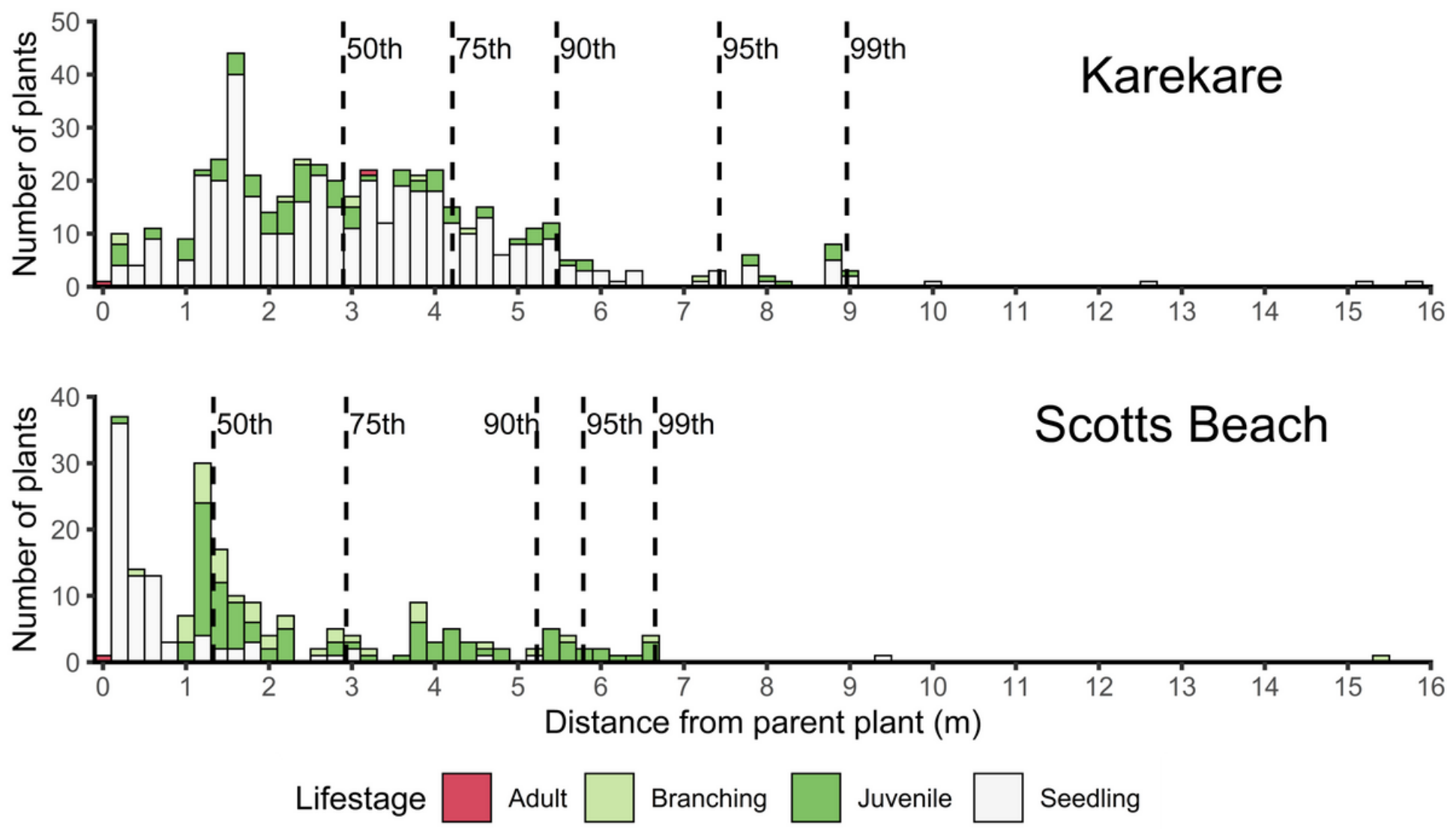

Figure 2

Effective dispersal kernels of Euphorbia paralias (sea spurge) at Karekare in Auckland and Scotts Beach, Karamea. Red adults at $0 \mathrm{~m}$ indicate the adult plant. Lifestages are seedling (plants $<4 \mathrm{~cm}$ ), juvenile (single stem non-reproductive plants), branching (multi-stem non-reproductive plants) and adult (flowering and/or seeding plant). Dashed lines represent the percentiles 

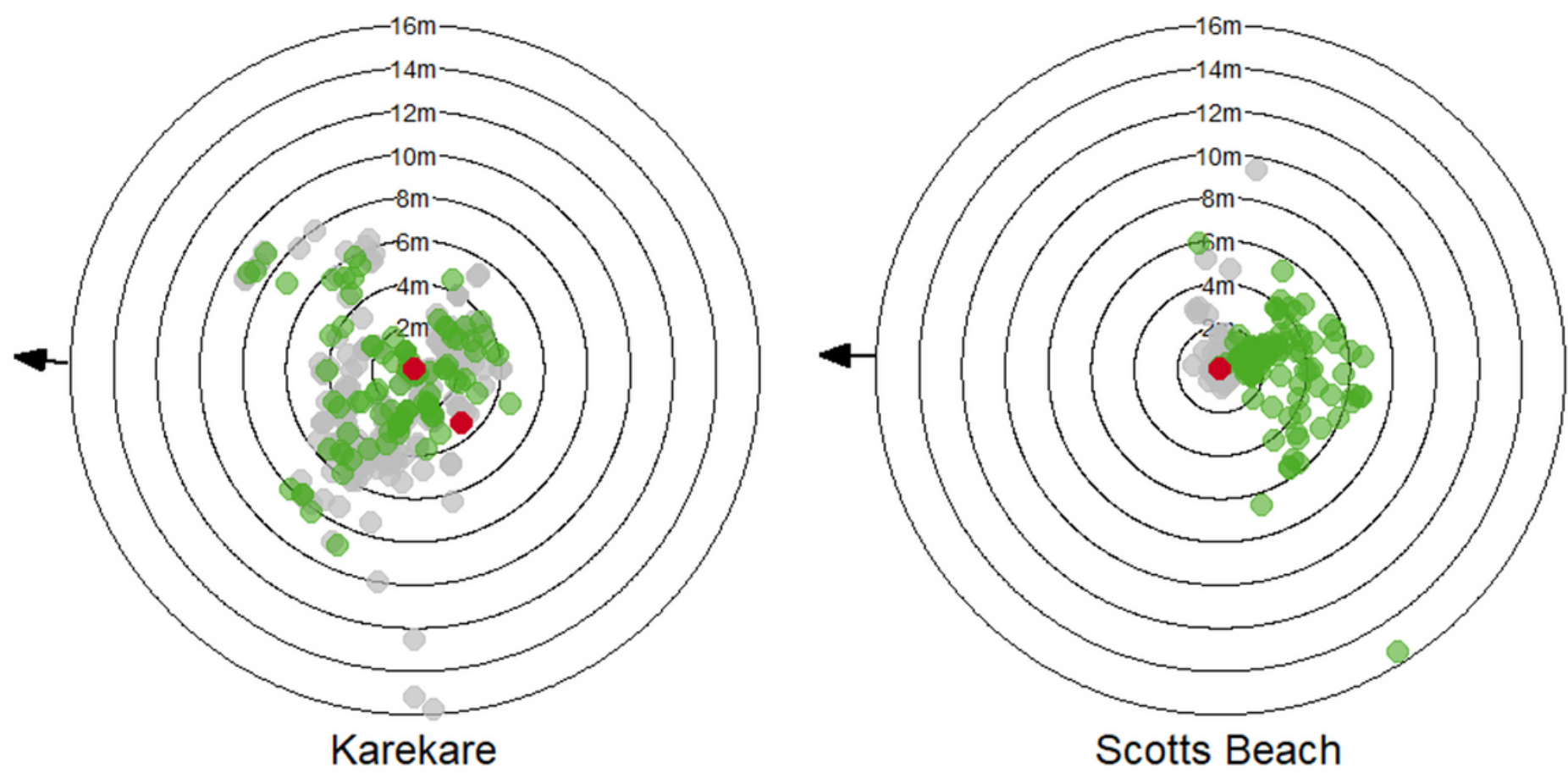

Figure 3

Spatial distribution (bird's-eye view) of Euphorbia paralias (sea spurge) plants at Karekare (left) and Scotts Beach (right). Grey points represent seedlings (plants $<4 \mathrm{~cm}$ ), green points represent juveniles (single or multi-stem non-reproductive plants) and red points represent adult plants (flowering and/or seeding) Red adults at $0 \mathrm{~m}$ indicate the adult plant which is the presumed parent of all other plants. (Note at Karekare a second adult plant was present but had only immature flowers). Circles represent distances from adult plant measured in metres. Black arrows point towards direction of the sea 